\title{
Disabled People as Culturally Relevant Teachers
}

\section{Gail Pritchard}

Griffith University

\begin{abstract}
This paper contends that disabled teachers are in such short supply as to be invisible even amongst minority teachers from already vastly marginalised populations. This is not simply because discriminatory practices are embedded within employment policies of educational systems, but deeply held socio-cultural attitudes also prevent disabled people accessing and attaining basic and later, higher levels of academic achievement. The central argument here is a simple one; disabled people as teachers offer a unique knowledge standpoint, challenge the animosity of dominant cultural beliefs around disability as analogous with passivity or non-achieving, and provide a source of resistance, solace and resolution for students they teach. Disabled people as educators enact exemplary pedagogic justice and socially inclusive practice. The aim of this paper is to explore the benefits to students and places of higher education alike of embracing both the person and the role of the teacher with disability as culturally relevant educators.
\end{abstract}

Keywords: minority teachers, marginality, disability, cultural relevance, higher education

Who a person is and what a person brings matters, and, indeed, is at the heart of what it means to be a teacher. (Palmer, 2007, p. 7)

This paper contends that disabled teachers are in such short supply as to be invisible even amongst minority teachers from an already vastly marginalised population. This is not simply because discriminatory practices are embedded within employment policies of educational systems, but deeply held socio-cultural attitudes also prevent disabled people accessing and attaining basic and later, higher levels of academic achievement. The central argument here is a simple one: disabled people as teachers offer a unique knowledge standpoint; challenge the animosity of dominant cultural beliefs around disability as analogous with passivity; and provide a source of resistance, solace and resolution for students they teach. Disabled people as educators enact exemplary pedagogic justice within the current culturally valued landscape of socially inclusive practice. 
The plethora of research data and documentation around issues of equity in education has centred largely on the provision of opportunities for students to access all levels of education. The term 'minority status' in western countries has generally become a euphemism for indigenous peoples, or those whose ethnic, racial, gender or sexual identity is different from the (white hetero-normative male) dominant identification (Minow, 1990).

The role of the 'minority' status teacher in contributing to curriculum design and delivery, education policy and practice, and employment in education recruitment and staff development is grossly under-researched. This is especially true of disabled people's access to and contribution within the education sector. The impoverished position of many disabled adults and families supporting a child with disability creates an income chasm which dismisses the aspirations let alone the discussion of continued education. This together with deeply held socio-cultural attitudes prevents many disabled people accessing and attaining basic and later, higher levels of academic achievement. The aim of this paper is to explore the benefits to students and places of higher education alike of embracing both the person and the role of the teacher with disability as culturally relevant educators. Ladson-Billings (1995) argues that culturally relevant teaching is a "pedagogy of opposition...specifically committed to collective, not individual, empowerment" (p. 160). It is this tension which creates and promotes the engagement and interaction between teachers and students for the benefit of all.

Some researchers in the field of 'diversity in education' have posited the idea that the more representative the teacher is of socially privileged members of society they can only be a traveller, a visitor of sorts when raising issues of racism, sexism or ableism in the educational environment (Weinstein \& Obear, 1992). Others may say that critical race studies, disability studies, cross-cultural and gender studies can only rightly and credibly be taught by people whose subject and content knowledge emerges from personal experience of marginality and marginal group identification. Matthews (1998) explores the notion of epistemic privilege:

... a term which refers to insider knowledge embodied in the locations, standpoints and positions of, for example, sex, race, culture, ethnicity, sexual preference, class, language, nation, political affinity and/or geography. It calls forth trust, belief and desire for knowledge and understanding grounded in experience and perception. (p.109)

This would give the disabled teacher, indigenous teacher, immigrant teacher knowledge standpoints which are indisputable and a particular licence to teach in their respective fields and possibly beyond. Teaching disability studies for example, need not be isolated from other explorations of marginality:

As teachers we can offer our experience with both dominant and targeted identities as a way to join with students, expand the boundaries in the room for discussing these subjects, and model being open to exploring our own relative positions of power and privilege in relation to different oppression issues. (Bell, Washington, Weinstein \& Love, 1997, p. 300)

However it is important to recognise that 'minority' teachers in Australia's higher education sector are merged within the overall population of the academic professionate and many do not have any association at all in teaching specifically around diversity issues. What is also important to note here is the distinct influence they have as role models, sources of resistance, solace and resolution for the students they teach. The value of this presence for students should not be underestimated. Seeing 'oneself' reflected in the classroom can be a life-changing experience for a student with disability. For marginalised and minority group 
students the disabled teacher can represent optimism that obstacles can be met and challenged, if not overcome. Additionally minority and other students can benefit from the interaction and engagement with life experience perspectives which differ from their own (Salinas, 2002).

\section{Knowledge Standpoint in Teaching Practice}

When I step into the lecture theatre or tutorial room I am acutely aware that I am a 'minority status' teacher. When teaching disability studies I am also acutely aware of my experiential knowledge standpoint. I have lived all my life as a person with disability, so I have some 'street cred', having encountered the gamut of assumptions about my intellect, my academic capacities, abilities to make the 'grade' and all of which in most part I've countered, if not managed. I have in my teaching journey discovered previously unrecognised prejudices within myself along with the recognisable prejudices of those in assumed privileged notdisabled communities of academia. When unlocking the Pandora's Box of discussion about oppression I do not want to be thought of as racist, homophobic, sexist, classist, or ableist (Bell et al., p. 301). Surely my minority status alleviates this risk? Do I have, because of my disability identity some sort of privileged access to a truth, or all truths about disability? Certainly not. All disabled people are not homogenous in identity, some even acknowledge and identify their multiple selves including gender, ethnicity and sexual preference. In my disability identity my personal biases are continually challenged through the teaching sojourn. Inherent in the challenging however is the promise of the imparting of the learning to our students:

As we confront misinformation or ignorance and the blindspots of privilege, we create the possibility for modelling honesty and openness to what can be learned by listening to others who are different from us, especially those who have been targets of dominant stereotypes and assumptions. (Bell et al., 1997, p. 304)

Disability knowledge standpoint offers a unique educative experience for students and importantly, for the revealing of previously suppressed voices:

Pedagogy is also shaped by our life experiences. Teachers with disabilities offer knowledge through their bodies and experiences that isn't usually part of the curriculum. Disabled teachers embody pedagogies of justice, interdependence, and respect for differences. Teaching (with) disability reveals spaces in education that often get silenced. (Anderson, 2006, p. 368)

These 'spaces' are the heartbeat of knowledge standpoint and "teachers with disabilities offer 'bodies of possibility' that interrogate and transform the spaces of academe" (Anderson, 2006, p. 378).

I would like to 'borrow' some salient observations from teachers and researchers in the fields of race and gender studies. Some time ago I came across an entry in Barbara Howe’s ‘Lucky White Girl’ blog:

To me, what standpoint theory says is simply that someone's given social position within the dominant structure of society makes it more or less likely that they will have a view of the world that is more or less critical of that dominant structure. It's not a hard or fast rule. But your chances of getting someone who really knows and understands oppression is better with someone who has more likely experienced it 
themselves. Not always. Some white men are better than some black women at understanding sexism and racism. But not usually. (2006, para. 9)

"Not always", "But not usually", why? I believe the answer lies in absolute, undeniable acts of voice and visibility. Here I am not necessarily referring to the nature of a person's impairment as being either visible or invisible, but rather the need to combat administrative, attitudinal, and policy-driven acts of exclusion. To embrace engagement in inclusive practices everywhere in the educative setting, and importantly to encourage our notdisabled peers to travel this course with us. Anderson (2006) identifies a significant teaching and learning benefit to disability disclosure and presence:

Teachers with disabilities have occasion to study disability and pedagogy together. The experience of disability has a generative impact on shared teaching and learning. That is, dynamic encounters shape what happens in the classroom. These encounters may happen when the professor's impairment is obvious or when one chooses to selfdisclose. Such opportunities reinforce interdependence between disabled and nondisabled learners. (p. 373)

The author recognises the particular hesitancy many people with disabilities feel about disclosing their disability status to their employing body. Many of us have faced discrimination (direct and indirect) and even been ostracised from social and professional interaction. Certainly those amongst us with visible impairments may experience injustices in ways that are different to those whose impairment is invisible; there may be assumptions made about degrees of 'support' required, uninformed opinion about how 'disability' will affect other staff, or misinformation about expenditure required for an accessible work environment. For people whose impairment is invisible support options may be harder to achieve, requirement for assistance discounted or overlooked and the apprehension and fear associated with disclosing a mental illness for example, so great as to silence and isolate the individual further. Our active collaboration with colleagues in social justice and social inclusion pedagogy should work to strengthen the value of disability knowledge standpoint and recognise the dehumanising acts of exclusion. As Barton (2004) strongly suggests "segregation is never benign; it is always associated with devaluation" (p. 30).

Reflection on the experiences that have shaped our identity is a fruitful and often confronting act, but it is not enough. My identity needs a true voice not just a representative place on the myriad of committees, annual festivals, 'special' days, community and government events, but an ongoing physical presence; the voice encompassed in a persistent visibility which cannot be dismissed or silenced. Knowledge standpoint must be engaged in and accompanied by visibility. Until recently I held a position in a research intensive school in a university faculty predominantly engaged in bio-medical, epidemiological and biostatistical research collaborations and academic programs. I was an 'oddity' not just because of my humanities/art/education background, but because of my visibility as a disabled woman and being vocally 'out' about disability issues. The appallingly low rates of people with disability in our Australian institutes of higher education, as students and academic staff alike, requires that I practice my 'visibility' constantly. If we (people with disability) are not 'seen' within the university environment we are not counted ... in anything. We may presently be acknowledged, even mentored and respected by a handful of not-disabled academics, but the systemic issues of discrimination and oppression can go unchecked unless we increase our visible presence. My work involved improving the quality of teaching practice even in the face of the research/teaching divide. My visibility as a woman with disability enabled the discussion of diversity and social and educational justice across all 
programs and courses, with all staff. There may be 'discomfort' (for ourselves as teachers with disability and undoubtedly for others) associated with being visible, but the alternative only ensures continued exclusion from all levels of education and does nothing to challenge the exclusionary boundaries of the current dominant academic culture and ableist paradigm. As Matthews (1998) states:

My arguments do not revise the popular idea that marginal groups have been traditionally silenced and should be 'given voice'. It seems to me that such notions do little more than incorporate the marginal into the centre and thus fail to deal with material circumstances of exclusion. (p. 109)

The 'material circumstances' within the university environment include recruitment policies and practices which are in essence and delivery exclusionary to specific populations. For example, career path impediments. If advancement is commensurate with opportunity then examination of the authenticity of opportunities available to disabled teaching staff needs to be undertaken in a truthful, open manner and the attitudinal biases and resistance of senior staff challenged vigorously by all faculty. Any potential inequitable workload distribution also needs to be impeded. This last issue refers to a tendency for minority status academic staff to find themselves with increased workloads, over-inflated assignments in particular areas of service and often placed in a position of becoming the resident 'expert' in all issues related to marginality regardless of their expertise (Dooley 2003). The uniqueness of our voice and visibility needs to be given genuine places and spaces to engage with debate, ideas, argument and potentialities of growth:

A distinction must be made between a shallow emphasis on coming to voice, which wrongly suggests there can be some democratization of voice wherein everyone's words will be given equal time and be seen as equally valuable ... and the more complex recognition of the uniqueness of each voice. (hooks, 2009, p. 139)

\section{Really, how many Teachers with Disability do you know?}

A number of sources indicate that while the ethnic diversity of the school-aged population is increasing, the teaching population is becoming increasingly homogenous.” ( Dooley, 2003, p. 268)

Whilst referring to teacher demographics and arguing the need to increase the number of ethnically diverse staff in faculties offering Special Education programs, Dooley's point is a salient one which can be readily transferred to an examination of 'minority' culturally diverse, especially disabled, teaching staff across universities in Australia. Our universities enrol increasing numbers of international students and offer a range of educational and support programs to both domestic and international students for whom English is not the primary language. Recruitment policies and programs throughout the higher education sector have not necessarily sought to actively engage culturally diverse faculty: particularly absent is any emphasis about engaging people with disabilities in teaching or research positions.

The Commonwealth Department of Education, Employment and Workplace Relations (D.E.E.W.R.) maintains a national database of higher education statistics which includes full time equivalence, overall numbers, highest qualifications and academic organisational unit groups. Interestingly it also maintains statistics relating to Indigenous staff, age and gender, but not disabled staff. Information regarding the ethnicity of staff is often maintained by various equity/human resource functions within the institutions. For example, upon 
appointment to a university the new staff member may opt to 'self identify' their ethnic origin, or their status as an Australian Aboriginal or Torres Strait Islander on a specific form for equal opportunity and human resource data collection purposes. This is not the case for staff with disability unless the individual themselves requests some type of specific assistance thereby creating notice within the bureaucracy. Otherwise we are for all intents and purposes numerically and characteristically irrelevant. Our numbers are not known, our locations scattered and disparate, and our academic interests emerge usually through a sort of dogged determination to network regardless of obstacles. Idealised rhetoric of democratic positioning of equity and access policies is at odds with our earliest similarly idealised expectations of education.

From grade school on, we are all encouraged to cross the threshold of the classroom believing we are entering a democratic space- a free zone where the desire to study and learn makes us all equal. (hooks, 2009, p. 135)

The optimism in a child's early school years is as hooks suggests, borne of naïveté and inexperience and is immediately challenged as a student with disability and in later life. To engage in academic life as a teacher with disability is to not only dismiss that naïve belief but also to come face-to-face with:

... the 'incongruity' produced in the encounter between the tragic 'disability' discourses of science, medicine, charity and the media and the disability rights discourse of disabled people 'enjoying' themselves and their 'solidarity with each other while challenging the role that society has assigned us'. (Corker, 1999, p. 81)

\section{What is the Academic Community?}

The general tendency to associate community with supportiveness and social cohesion has been widely noted, but the word community may be used negatively as well as positively. Recognition has grown that community relationships have the potential to constrain individuals as well as to empower them, and to be exclusive as well as inclusive. Social divisions are as much based on unifying the membership of each particular category as in mutual opposition across social divides. (Crow \& MacLean, 2000, p. 234)

Affirmative action and specific equity policies which have been developed and enacted over the past two decades have been both a blessing and a curse. In terms of employment within higher education with regard to people with disabilities such policies ironically imply there is a critical mass of potential candidates suitably qualified and immediately ready to fill vacancies arising. However, the socio-economic-education status and thus 'work readiness' of disabled people presently in Australia is lamentable. Prevailing government schemes around vocational training and employment placement appear to miss the vital educational link from primary to secondary schooling and subsequent successful transition into higher education; neither do they understand the relationship between poverty and disabilities. Scull and Cuthill (2010) explain the Australian government's policy context:

Two important and interrelated perspectives, social justice and economic prosperity, drive the urgent imperative for more equitable access to higher education for students from low socio-economic backgrounds. This issue became focal point of public policy in countries such as Australia, the UK and the USA following World War II. 
Promoting an opportunity structure through educational attainment was a critical part of these early policies. The publication A fair chance for all, a Department of Employment Education and Training (1990) discussion paper, promoted development of a national higher education equity framework that continues to underpin equity objectives in Australian higher education. (p. 60)

Scull and Cuthill note that "For some students, engagement with the university experience is like engaging in a battle. These are students for whom the culture of the institution is foreign and at times alienating and uninviting” (p. 61), particularly where their class, ethnicity or prior educational opportunities have not provided the social capital by which to meet the social and academic expectations and competitive aspects of university life. These issues are similarly present for disabled people entering professional teaching and research positions. The 'culture' of the university and its inherent expectations often require the disabled staff member to prepare for battle each and every day. Bell et al. (1997, p. 308) assert that "issues of authority in the classroom are especially complicated for faculty who are members of targeted groups ... Students sometimes perceive them as less authoritative and may discount the legitimacy of what they teach or accuse them of pushing their own agenda”. This may be particularly applicable if the teacher is teaching around social justice or diversity course content. Corker (1999) equally argues that in the research arena the authority and quality of the disabled researcher's involvement may be questioned in the face of the dominant authoritative non-disabled professional institution and its constituency. She states that research "has inherent discursive privileging strategies which equate textual authority with both the identity of and the relationship between author and reader which produce particular kinds of contingent knowledge” (p. 76).

Although the personal and professional experiences of disabled and non-disabled teachers may have some points of similarity or convergence we need to return to concepts of standpoint theory and situated knowledge to recognise the sources and trajectory of difference. As Campbell (2009) states:

I argue that the question of situated knowledges has nonetheless a lurking omnipresence within the teacher's body and pedagogic practices. Although unstated, it has clear implications for the competitive academic job market, to say nothing about affirmative action employment strategies, the future of a vital leadership made up of disabled people and the ways the complexities and variabilities of the disability experience is marked and represented.whilst the education system has paid increased attention to the wellbeing of the disabled child, this concern has not been extended to promoting equal access for teachers with disabilities. (p. 719)

\section{Conclusion and Questions for the Present and Future}

Strategies for inclusion of disabled people within the teaching profession could be as varied as the individuals and educational institutions concerned (Haberman, 1989). Earlier in this paper I stated that much research around equity in higher education is directed towards students rather than academic teaching staff. The pathway for inclusion of disabled people into the teaching profession must begin with support for disabled students seeking qualifications to create a career path within the higher education sector. To that end I believe the following brief suggestions to be essential in the Australian context and the beginning of a truly socially inclusive process: 
- develop a financial support programme along the lines of ABSTUDY for disabled students wanting to advance to higher education but with an increased (non-taxable) component for equipment/technology;

- create solid, 'real' vocational opportunities for people with disability through partnerships with institutes of higher education (the current treadmill of training and re-training and short-term job placement contributes to individual and collective poverty not liberation);

- develop recruitment drives into teacher education within university-based programs; and

- form working partnerships between public and private schools and higher education institutes over the last two years of secondary education which emphasise access and support and educational attainment for minority students (the one hour 'talk' presented in the last term of high school dedicated to equity and opportunity is at its worst patronising and at best lacks specificity).

The promotion of higher education as part of the 'cultural world' of the student with disability alongside the promotion of the student with disability as part of the 'cultural landscape' of the academy will contribute to the future engagement and retention of teachers with disability.

Insights for pedagogy emerge when we consider disability as a valuable source of lived experiences, rather than see disabled bodies as 'something to be accommodated.

(Anderson, 2006, p. 369)

In examining the meanings of 'accommodation' as they relate to disabled teachers some essential questions must be answered. Can our current university academic 'communities' embrace and include disabled teachers as individuals pursuing professional careers? Can campus culture afford us the structural and environmental supports to navigate the current minefield of professional development and equity policies? Can the various schools and faculties within the higher education system begin to value the unique voice and visibility of the teacher with disability as contributing to the cultural relevance of their education programming? In social justice terms the social inclusion landscape before us must resonate with the cultural relevance of the disabled teacher and recognise the pedagogical frameworks which develop educational spaces that are safe, inclusive and liberatory (hooks, 1994).

\section{References}

Anderson, R.C. (2006). Teaching (with) Disability: Pedagogies of Lived Experience. Review of Education, Pedagogy \& Cultural Studies, 28, 367-379.

Barton, L. (2004). The politics of special education: A necessary or irrelevant approach. In L.Ware (Ed) Ideology and the politics of (in)exclusion. New York, NY: Peter Lang.

Bell, L.A., Washington, S., Weinstein, G., Love, B. (1997). Knowing Ourselves as Instructors. In M. Adams, L.A. Bell and P. Griffin (Eds.), Teaching for Diversity and Social Justice: A Sourcebook (pp. 299-310). New York: Routledge.

Campbell, F.K. (2009). Having a career in disability studies without even becoming disabled! The strains of the disabled teaching body. International Journal of Inclusive Education, 13, 713-725. 
Carr, P.A. \& Klassen, T.R. (1997). Different Perceptions of Race in Education: Racial Minority and White Teachers, Canadian Journal of Education, 22, 67-81

Corker,M. (1999). 'Disability'- The Unwelcome Ghost at the Banquet...and the Conspiracy of 'Normality'. Body \& Society, 5, 75-83.

Commonwealth of Australia, Department of Education, Employment and Workplace Relations (D.E.E.W.R.). Retrieved $19^{\text {th }}$ December, 2009, from http://www.deewr.gov. au/HigherEducation/Pages/default.aspx

Crow, G. \& MacLean, C. (2000) 'Community', in Payne, G. (Ed.), Social Divisions Hampshire: Palgrave

Dooley, E.A. (2003). Increasing the Number of Ethnically Diverse Faculty in Special Education Programs: Issues and Initiatives, Teacher Education and Special Education, 26, 264-272.

Haberman, M. (1989). More Minority Teachers, The Phi Delta Kappan, 70, 771-776.

hooks, b. (1994). Teaching to Transgress: Education as the Practice of Freedom. New York: Routledge Press.

hooks, b. (2009). Confronting Class in the Classroom. In A. Darder, M.P. Baltodano \& R.D.Torres (Eds.), The Critical Pedagogy Reader (2nd ed) pp. 142-150. New York: Routledge Press.

Howe, B. (2006, January 26). Whose knowledge? Standpoint theory, revisited. Lucky White Girl blog. Retrieved June 4, 2009, from http://barbhowe.typepad.com/lucky/2006/01/ whose knowledge.html

Ladson-Billings, G. (1995). But That's Just Good Teaching! The Case for Culturally Relevant Pedagogy, Theory Into Practice, 34,159-165.

Matthews, J.M. (1998). Fleeing the Self in Pursuit of the Other, Change: Transformations in Education, 1, 109-117.

Minow, M. (1990). Making All the Difference: Inclusion, Exclusion, and American Law. Ithaca: Cornell University Press.

Palmer, P.J. (2007). The Courage to Teach: Exploring the Inner Landscape of a Teacher's Life. San Francisco: Jossey-Bass.

Salinas, J.P. (2002). The Effectiveness of Minority Teachers on Minority Student Success, National Association of Hispanic and Latino Studies: 2000 Literature Monograph Series, 604-626. National Association of African American Studies, Houston.

Scull, S. \& Cuthill, M. (2010). Engaged outreach: using community engagement to facilitate access to higher education for people from low socio-economic backgrounds, Higher Education Research \& Development, 29, 59-74.

Stoetzier,M. \& Yuval-Davis, N. (2002). Standpoint theory, situated knowledge and the situated imagination, Feminist Theory, 3, 315-33.

Washington, S.J. (2000). "Give Me My 'Props': Race, Gender and Authority in the Classroom”. People of Color in Predominantly White Institutions, Building Diversity in the University and the Community - Fifth Annual National Conference. University of Nebraska, Lincoln.

Weinstein, G., \& Obear, K. (1992). Bias Issues in the Classroom: Encounters with the Teaching Self, New Directions for Teaching and Learning, 52, 39-50.

\section{Biographical Note}

Gail Pritchard has been teaching in Disability Studies for over a decade and is sessional lecturer at Griffith University. She has been an activist, community educator, and teacher since the 1980's. Recently she held the position of Teaching Development \& Disability Liaison Officer, School of Population Health, University of Queensland. 